\title{
Starch Properties and Structure of A Wheat Mutant High in Resistant Starch
}

\author{
Limeng Jia ${ }^{1}$, Zhizhuan Zhang ${ }^{1}$, Xiaoli Shu ${ }^{*}$, , Chengdao $\mathrm{Li}^{2}$ and Dianxing $\mathrm{Wu}^{*}{ }^{* 1}$ \\ ${ }^{I}$ IAEA Collaborating Center, Institute of Nuclear Agricultural Sciences, Zhejiang University, Hangzhou 310029, \\ P.R. China \\ ${ }^{2}$ Agricultural Research Western Australia, Department of Agriculture and Food, Government of Western Australia, \\ South Perth, WA6151, Australia
}

\begin{abstract}
Starch properties and structure of a wheat mutant (WRS-1) high in resistant starch (RS) was compared to that of the wild type (Sumai No.6). In cooked hot flour and retrograded flour, the amounts of RS in mutant WRS-1 were 7.8 and 9.4 times of wild type ( 0.5 in hot flour and 0.6 in retrograded flour), respectively, and correspondingly the slower and incomplete starch hydrolysis was also in both types of samples. WRS-1 had a higher $\lambda$ max of absorbance, blue value (BV), apparent amylose content (AAC), and contained the increased intermediate and long chains with $18 \leq$ degree of polymerization (DP) and decreased short chains with DP $\leq 17$. Two types of starch granules, large A in lenticular shape and small B in spherical shape, were observed in both mutant and wild types. However, the starch granules in WRS-1 were relatively larger and some were irregularly-shaped. High content of total starch (TS), decreased contents of lipid (LC) and protein (PC), lower onset temperature $\left(T_{o}\right)$, peak temperature $\left(T_{p}\right)$, final temperature $\left(T_{c}\right)$, and the enthalpy of gelatinization $\left(\Delta H_{g e l}\right)$ were observed in WRS-1.
\end{abstract}

Keywords: Wheat, resistant starch, starch properties, starch structure.

\section{INTRODUCTION}

Starch is the primary source of dietary carbohydrate and energy intake [1-2]. In a view of starch digestion, common starch contains a higher percentage of digestible fraction (digestible starch, DS) and a lower percentage of the nondigestible fraction called as enzymatic resistant starch (RS) in the major staple starchy crops such as rice and wheat [35]. RS is defined as 'the sum of starch and the products of starch degradation not absorbed in the small intestine of healthy individuals' [6]. The slowly digested RS results in decreased postprandial glucose and insulin responses, which is beneficial for a person with diabetes and hyperlipidemia [7-12]. The RS fermented in the colon may produce many short-chain fatty acids (SCFA) that are helpful in preventing colonic diseases [12-16].

Wheat is a major cereal crop that is used as a food ingredient in bread, noodles and many bakery products [17]. The RS contents were very low with $0.08 \%$ in the native wheat flour [18], $0.3 \% \sim 1.0 \%$ in wheat flour bread and white bread [19], and $0.54 \% \sim 1.03 \%$ in wheat-based poori by different treatments [20]. A novel high-amylose barley cultivar (Hordeum vulgare var. Himalaya 292) with altered starch synthesis and less total starch but more amylose and RS were found to lower plasma cholesterol and alter the indices of large-bowel fermentation in pigs [14]. High-amylose wheat generated by RNA interference was reported to improve the indices of large-bowel health in rats [21]. These results indicate that high-amylose barley and wheat have significant potential to improve human health through its resistant starch content. However, high-amylose grains are poor in eating

*Address correspondence to these authors at the IAEA Collaborating Center, Institute of Nuclear Agricultural Sciences, Zhejiang University, Hangzhou 310029, P.R. China; Tel: ++86-571-86971405; Fax: ++86-57186971202; E-mail: dxwu@zju.edu.cn; shuxi@zju.edu.cn quality and the starch is generally used as an additive for the food industries in most cases. To increase the RS in bread, high-amylose wheat/maize flour or wheat bran was used as an additive in bread making [22-24], or the normal starch was physically or chemically modified before being processed [25]. However, carbohydrate consumption from white bread is five times that of the whole wheat [26], which has benefits by reducing the glucose, insulin and blood lipids [27].

In the context of globally increasing levels of obesity and diabetes [28], breeding for staple food crops such as wheat, rice and other starchy crops with high RS content and better quality is of particular interest, as they have great impacts on the dietary prevention of diabetes and hyperlipidemia [5]. High-RS mutant rice was identified in our previous studies $[5,29]$. A simplified methodology suitable for screening the starchy crops high in RS indirectly was established, and a high-RS wheat mutant (WRS-1) with intermediate content of amylose was isolated from a commercial variety 'Sumai No.6' in Huihe River valley of China. In the current paper, starch properties and structure of this mutant were comparatively studied with the wild type, which will provide information for plant breeders to improve RS in wheat and for food technologists to develop high-RS wheat-based foodstuffs.

\section{MATERIALS AND METHODOLOGY}

\section{Materials}

Wheat mutant 'WRS-1' high in resistant starch was identified from the commercial wheat variety 'Sumai No.6' by induced mutation. Briefly, the dry seeds with $13.5 \%$ seed moisture were irradiated by 300 Gy Cobalt- 60 gamma rays. The resulting irradiated seeds were directly sown in the field and at maturity seeds were bulkily harvested from each $\mathrm{M}_{1}$ 
plant. The $\mathrm{M}_{2}$ seeds were sown on a seedling bed and then seedlings were individually transplanted into the field at the $5^{\text {th }}-6^{\text {th }}$ leaf-age stage. At maturity seeds were individually harvested for preliminary screening plants high in resistant starch. The isolated candidates were grown into $\mathrm{M}_{3}$ plant lines for further verification of real mutations. In the subsequent three generations at $\mathrm{M}_{4-5-6}$, the stabilities of identified mutant mutation high in resistant starch were evaluated among environments. One of mutant labeled as WRS-1 at $\mathrm{M}_{7}$ generation was used for the current study. 'Sumai No.6' is widely planted in the Huihe River Valley of China.

\section{Sample Preparation}

Wheat grains were dehulled by hand and then ground to whole-meal flour using a Quadrumat Jr. Mill (Brabender, Duisburg, Germany). The resulting flour was sieved with a 100-mesh for apparent amylose content (AAC), crude lipid content (LC), protein content (PC), DSC thermal properties, total starch (TS) and resistant starch (RS) analysis. Starch was isolated by a $\mathrm{NaOH}$ method described by Verwimp, Vandepytte and Marrant [30]. The isolated starches were dried on an oven at $40^{\circ} \mathrm{C}$ for $24 \mathrm{~h}$ and the resulting starches were gently sieved with 100-mesh and stored in a sealed plastic bag for starch morphology scanning. According to practical applications in daily life and food industries, freshly hot processed and retrograded samples were chosen for this analysis. The freshly hot cooked flour were prepared with the ratio of water to flour 4:1 and cooked 20 mins in boiling water by a Cooker and then kept in warm-holding status $\left(\right.$ at $\left.50^{\circ} \mathrm{C}\right) 10$ mins. The freshly cooked flour was kept under room temperature for $24 \mathrm{~h}$ as retrograded samples.

\section{Apparent Amylose, Total Starch, Resistant Starch, Lipid and Protein Determination}

AAC was determined according to the method based on the amylose-iodine blue value at $\lambda=620$ [31]. LC was determined by the AACC method [32] and PC was measured with the microkjeldahle method [31]. The contents of RS in the hot and retrograded samples were determined by a Megazyme RS Kit (Megazyme International Ireland Ltd., Co. Wicklow, Ireland). TS was determined according to the protocol described by Garcia-Alonso et al. [33].

\section{In Vitro Kinetics of Starch Digestion}

In vitro starch hydrolysis was determined according to Goñi et al. [34] with minor modifications. After incubating with 300 IU pepsin (Amresco) for $1 \mathrm{~h}$, starch hydrolysis was initiated by adding $3.0 \mathrm{IU}$ porcine pancreatic alpha-amylase (Megazyme) in Na-K phosphate buffer. The final volume was $30 \mathrm{ml}$. The reaction mixture was incubated at $37^{\circ} \mathrm{C}$ with moderate agitation. Two aliquot of $0.5 \mathrm{ml}$ solution were taken from each flask every $30 \mathrm{~min}$ from 0 to $3 \mathrm{~h}$ and the alpha-amylase inactivated by adding $0.5 \mathrm{ml} 1.2 \mathrm{M}$ glacial acetic acid. The total reducing sugar was determined by the DNS regent (3,5-dinitrosalicylic acid). The extent of hydrolysis was calculated as the percentage (\%, maltose equivalent) of starch degraded to maltose in total starch. Each sample was analyzed in triplicate.

\section{Differential Scanning Calorimetry (DSC)}

The thermal properties of flour isolated from wheat were determined using a differential scanning calorimeter (DSC)
(Q100T, TA Inc., Newcastle, DE) and calculated with the Universal Analysis program, version 3.8B. Five-milligram samples were placed in an aluminum cup, and $20 \mu \mathrm{L}$ of distilled water was added. The cup was hermetically sealed and then heated from $30^{\circ} \mathrm{C}$ to $110^{\circ} \mathrm{C}$ at a rate of $10^{\circ} \mathrm{C} / \mathrm{min}$. The major parameters of the DSC profile were described as onset temperature $(T \mathrm{O})$, peak temperature $(T \mathrm{P})$, enthalpy of gelatinization ( $\triangle H \mathrm{Hel})$, and final temperature $(T C)$.

\section{Scanning Electron Microscope}

Starch powders were homogeneously stuck on doubleadhesive tape fixed on a metallic stub, then treated in an IB-5 Ion Coater (Eiko Co., Japan) for 30 min under argon atmosphere, coated with the Pt ion, and visualized with a scanning electron microscope (XL30ESEM, Philips Co., Holland) at $20 \mathrm{kV}$. Micrographs of starch samples were taken at $500 \times$ magnification, and the sizes of starch granules in three of randomly selected scopes were measured in the Adobe Photoshop Elements 2.0.

\section{X-Ray Diffraction Pattern}

$\mathrm{X}$-ray diffraction patterns of the wheat flour were measured with copper $\mathrm{K} \alpha$ radiation $(\lambda=0.154 \mathrm{~nm})$ using a diffractometer (D/max 2550PC, Rigku Inc., Japan) equipped with the Universal Analysis software, Version 3.8B. The diffraction was operated at $30 \mathrm{~mA}$ and $40 \mathrm{kV}$. The region of twotheta angle $(2 \theta)$ was scanned over the range from 3.0 to $70.0^{\circ}$ with a $0.05^{\circ}$ of step size and a count time of $2 \mathrm{~s}$. The estimated cystallinity was analyzed by assessing the contribution of amorphous features to the total diffraction intensity over the angular range $5-35^{\circ} 2 \theta$ with the SigmaPlot software (SYSTAT, USA).

\section{Chain-Length of Amylopectin}

Milled wheat flour was debranched as described by Umemoto et al. [35] and the amylopectin chain-length (ACL) distribution profile determined by high performance anion exchange chromatography with pulsed amperometric detection (HPAE-PAD) [36].

\section{Statistical Methods}

The data obtained were subjected to one way analysis of variance followed by Duncan's multiple-range tests.

\section{RESULTS AND DISCUSSIONS}

\section{Resistant Starch and In Vitro Hydrolysis}

RS and glycemic index (GI) are two indicators important for starch digestibility. In numerous studies, $\mathrm{RS}$ is used as a predictor of slow release of glucose and GI is predicted by in vitro model of starch hydrolysis [34, 37-38].

The RS contents in WRS-1were $3.82 \%$ in hot wheat flour and $5.36 \%$ in retrograded flour (Table 1). The amounts of RS were significantly increased as 7.8 and 9.4 times of that of wild type $(0.5 \%$ in hot wheat flour and $0.6 \%$ in retrograded flour) respectively. The extent of RS enrichment caused by starch retrogradation was also different between mutant WRS-1 and wild type, although the enrichments of RS were observed as expected usually. There was 1.4 times of RS enrichment in retrograded sample of mutant WRS-1, but only 1.2 times in wild type. 
Table 1. Physiochemical Properties, Lipid and Protein Content in Mutant WRS-1 and Wild Type

\begin{tabular}{|c|c|c|c|c|c|c|c|c|c|c|c|c|c|c|c|c|c|c|}
\hline \multirow{2}{*}{ Materials } & \multirow{2}{*}{ TS $(\%)$} & \multirow{2}{*}{$\begin{array}{l}\text { RS in Hot } \\
\text { Flour }(\%)\end{array}$} & \multirow{2}{*}{$\begin{array}{c}\text { RS In } \\
\text { Retrograded } \\
\text { Flour }(\%)\end{array}$} & \multirow{2}{*}{ AAC (\%) } & \multirow{2}{*}{ LC (\%) } & \multirow{2}{*}{$\mathrm{PC}(\%)$} & \multicolumn{3}{|c|}{$\begin{array}{l}\text { Iodine-Binding Starch } \\
\text { Properties }\end{array}$} & \multicolumn{4}{|c|}{ Thermal Properties } & \multirow{2}{*}{$\begin{array}{c}\text { Crystallinity } \\
(\%)\end{array}$} & \multicolumn{4}{|c|}{$\begin{array}{l}\text { Chain-Length Distribution of } \\
\text { Amylopectin }\end{array}$} \\
\hline & & & & & & & $\lambda_{\max }(\mathrm{nm})$ & \begin{tabular}{|l|}
$\mathbf{B V}_{680 \mathrm{~nm}}$ \\
\end{tabular} & \begin{tabular}{|l|l|}
$\mathbf{A}_{620 \mathrm{~nm}}$ & \\
\end{tabular} & $T_{o}\left({ }^{\circ} \mathrm{C}\right)$ & $T_{P}\left({ }^{\circ} \mathrm{C}\right)$ & $\begin{array}{|ll|}T_{C} & \left({ }^{\circ} \mathrm{C}\right) \\
\end{array}$ & $A H_{g e l}(\mathrm{~J} / \mathrm{g})$ & & $\mathrm{DP} \leq 12$ & $13 \leq \mathrm{DP} \leq 24$ & $25 \leq \mathrm{DP} \leq 36$ & $\mathrm{DP} \leq 37$ \\
\hline $\begin{array}{c}\text { WRS-1 } \\
\text { (mutant) }\end{array}$ & $76.8 \pm 0.3^{* *}$ & $3.8 \pm 0.1 * *$ & $5.4 \pm 0.2 * *$ & $18.4 \pm 0.3^{*}$ & $1.7 \pm 0.1^{* *}$ & $12.8 \pm 0.2^{*}$ & $591 *$ & 0.23 & 0.29 & $56.6 \pm 0.1^{*}$ & $61.9 \pm 0.1 *$ & $66.8 \pm 0.1 *$ & $5.0 \pm 0.1^{*}$ & $26.3 \pm 0.2$ & $49.4 * *$ & 38.8 & $7.2^{* *}$ & $4.6^{* *}$ \\
\hline $\begin{array}{l}\text { Sumai No.6 } \\
\text { (wild type) }\end{array}$ & $69.0 \pm 0.2$ & $0.5 \pm 0.2$ & $0.6 \pm 0.2$ & $15.9 \pm 0.4$ & $2.7 \pm 0.1$ & $16.1 \pm 0.2$ & 586 & 0.20 & 0.26 & $58.8 \pm 0.0$ & $63.9 \pm 0.1$ & $68.5 \pm 0.1$ & $5.2 \pm 0.1$ & $26.6 \pm 0.2$ & 40.4 & 39.0 & 10.4 & 10.2 \\
\hline
\end{tabular}

Note: (1) TS: total starch; RS: resistant content; AAC: apparent amylose content; LC: crude lipid content; PC: protein content; BV: blue value (absorbance at $\lambda=680 \mathrm{~nm}$ ); A620nm: absorbance at $\lambda=620 \mathrm{~nm}$, where AAC was determined; $T_{o}$ : onset temperature; $T_{c}$ : final temperature; $T_{p}$ : peak temperature; $\Delta H_{g e l}$ : the enthalpy of gelatinization; DP: the degree of polymerization. (2) ${ }^{*}$ and ${ }^{* *}$ stand for significant differences at $p 0.05$ and $p 0.01$ levels, respectively, compared to that of wild type.

Correspondingly, the rate and extent of in vitro hydrolysis of starch were different between mutant and wild type. The starch from WRS-1, especially the retrograded sample, was highly resistant to hydrolysis and tended to be hydrolyzed in a slower rate and a lower degree than that of 'Sumai No.6' (Fig. 1). The retrograded sample of WRS-1 needed 120 mins to reach the equilibrium of starch hydrolysis, significantly longer than other three samples. At the final time of 180 mins, only $73.8 \%$ and $79.2 \%$ of starch had been hydrolyzed in the hot and retrograded samples of WRS-1, respectively, whereas $91.8 \%$ and $94.7 \%$ of 'Sumai No.6' had been hydrolyzed.

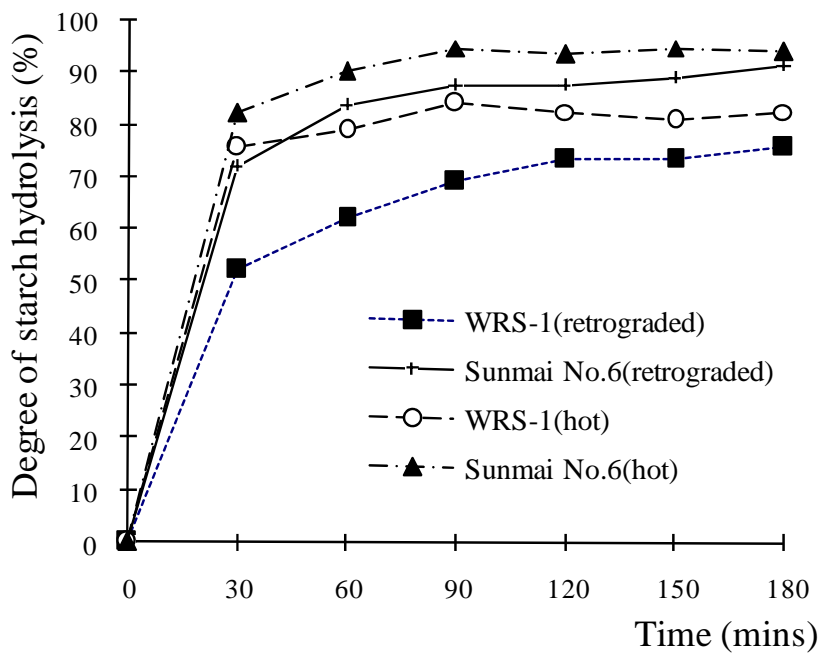

Fig. (1). In vitro hydrolysis of hot and retrograded flours produced from mutant WRS-1 and wild type 'Sumai No.6'.

Concurred with the previous reports in rice [5, 29], the higher level of RS and lower rate of in vitro hydrolysis was observed simultaneously in WRS- 1 . Similar to the result above and previous studies on the influences of retrogradation on RS [39-40], slow hydrolysis was observed in hot and retrograded samples.

\section{Physicochemical Properties, Thermal Properties and X- Ray Diffraction}

Higher contents of the TS and AAC were detected in mutant WRS-1, compared to that of wild type (Table 1). This result was consistent with the previous studies that high RS was reported to correspond with relatively high levels of amylose in rice, corn, wheat, and barley [4, 14, 21, 41]. Different from the previous reports that high amylose starch was found more prone to form amylose-lipid complex, and the enhancement of RS might be caused both by the increased amylose starch and by amylose-lipid complex in mutant rice RS111 (5), LC and PC were obviously decreased in WRS-1.

The DSC parameters $T_{o}, T_{p}, T_{c}$ and $\Delta H_{g e l}$ of mutant were lower than that of wild type (Table 1), however the decreased extent of DSC parameters in WRS-1 seemed to be somewhat different from characteristics in mutant rice high in RS.

As denoted by its characteristic reflections at $2 \theta$, the Xray diffraction of wheat flour showed the typical A-type crystalline pattern. The cystallinity in WRS- 1 was low than that of wild type (Table $\mathbf{1}$ and Fig. (2)). The high degree of cystallinity needed high transition temperatures to disorder the crystal. Relatively low cystallinity in WRS-1 supported the above results on thermal properties.

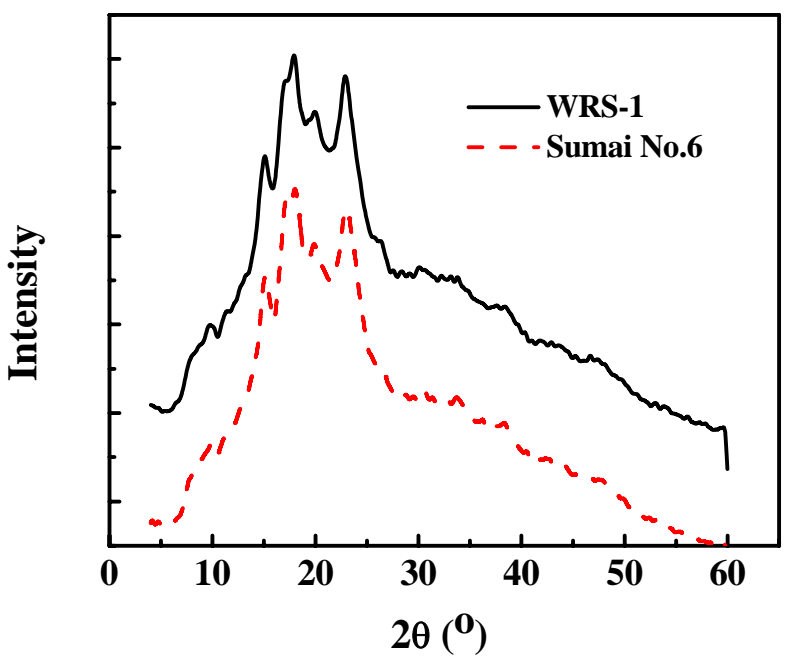

Fig. (2). X-ray diffraction pattern of flours from mutant WRS-1 and wild type 'Sumai No.6'.

\section{Starch Granule Morphology}

Scanning electron micrographs (SEM) showed that both mutant and wild type had two types of starch granules, large A in lenticular shape and small B in spherical shape as the previous report [42], whereas a few irregular-shaped granules were observed in WRS-1 (Table 2 and Fig. (3)). The average diameters of A- and B-shaped granules in WRS-1 were $19.5 \mu \mathrm{m}$ and $6.6 \mu \mathrm{m}$, respectively, relatively larger than that of wild type that had A-shaped in an average diameters of $17.2 \mu \mathrm{m}$ and B-shaped in an average diameters of $4.9 \mu \mathrm{m}$. The result above from SEM was consistent with the previous reports in which significantly higher proportion of larger starch granule was observed in some wheat variety [43]. The larger starch granules were more resistant to enzymatic digestion and the irregular granule was a typical characteristic of high RS [44]. 
Table 2. Shape and Size of Starch Granule in Mutant WRS-1 and Wild Type 'Sumai No.6'

\begin{tabular}{|c|c|c|c|c|c|c|}
\hline Materials & $\begin{array}{c}\text { No. Granules } \\
\text { Observed }\end{array}$ & $\begin{array}{c}\text { Shape Type of } \\
\text { Starch Granule }\end{array}$ & $\begin{array}{c}\text { Range of Lenticular } \\
\text { Shape }(\boldsymbol{\mu m})\end{array}$ & $\begin{array}{c}\text { Average Size of } \\
\text { Lenticular Shape }(\boldsymbol{\mu m})\end{array}$ & $\begin{array}{c}\text { Range of } \\
\text { Spherical } \\
\text { Shape }(\boldsymbol{\mu m})\end{array}$ & $\begin{array}{c}\text { Average Size of } \\
\text { Spherical } \\
\text { Shape }(\boldsymbol{\mu m})\end{array}$ \\
\hline \hline $\begin{array}{c}\text { WRS-1 } \\
\text { (mutant) }\end{array}$ & 481 & $\begin{array}{c}\text { Lenticular, spherical } \\
\text { and irregular }\end{array}$ & 12.5 to 34.7 & 19.5 & 2.8 to 9.1 & 6.6 \\
\hline $\begin{array}{c}\text { Sumai No.6 } \\
\text { (wild type) }\end{array}$ & 502 & $\begin{array}{c}\text { Lenticular and } \\
\text { spherical }\end{array}$ & 11.7 to 32.5 & 17.2 & 1.3 to 8.5 & 4.9 \\
\hline
\end{tabular}

\section{Chain Length of Amylopectin}

Based on the degree of polymerization (DP), the side chains of amylopectin can be classified into four fractions such as $\mathrm{DP} \leq 12,13 \leq \mathrm{DP} \leq 24,25 \leq \mathrm{DP} \leq 36$ and $37 \leq \mathrm{DP}$, which corresponds to A, B1, B2, B3 and longer chains [36]. Compared to wild type, mutant WRS-1 had the increased intermediate and long chains with $18 \leq \mathrm{DP}$ and decreased short chains with $\mathrm{DP} \leq 17$, especially $8 \leq \mathrm{DP} \leq 10$ (Table $\mathbf{1}$ and Fig. (4)). This result was also similar to the previous reports by Shi et al. [45] and Salomonsson et al. [46], in which short chains with $6 \leq \mathrm{DP} \leq 19$ were found to inhibit the retrogradation of starch, and the higher percentage of long chains of amylopectin was observed in high-amylose barley. The chain-length profile of amylopectin in WRS-1 was the same as the previous reports on the ae mutants in rice [47-48]. However, the amylopectin chain ratio (ACR, expressed by the ratio of total short chains with $\mathrm{DP} \leq 10$ to total intermediate chains with $\mathrm{DP} \leq 24$ ) was significantly lower in the mutant WRS-1 with an ACR value of 0.55 compared to the wild type with an ACR value of 0.66. According to the group classification described by Nakamura et al. [49], WRS-1 and wild type should be different types of amylopectin. Except the ACR, the discrepancy between WRS-1 and ae could be also reflected from the above $T o$ 。

\section{The Iodine-Binding Starch Properties}

In mutant WRS-1, the iodine-binding starch complex had a higher $\lambda \max$ of absorbance in $591 \mathrm{~nm}$, blue value (BV), and value of BV620nm minus BV680nm than that of wild type (Table 1 ). The absorbance at $\lambda=620 \mathrm{~nm}$ where AAC was determined was also higher in WRS- 1 as mentioned in the result above. The current concept on AAC described in the present study is composed actually of two components: amylose and partly branched long chains (B chains) of amylopectin. The higher AAC in WRS-1 was consistent with the increased long-chain distribution of amylopectin.

\section{CONCLUSIONS}

High RS wheat was characterized by the higher RS content and slower and incomplete starch hydrolysis in both of hot and retrograded flours. The RS increase in WRS- 1 is resulted significantly from starch properties and distinct starch structure such as higher AAC and TS, larger-and irregular-shaped starch granules, increased intermediate and long chains with $18 \leq \mathrm{DP}$ and decreased short chains with $\mathrm{DP} \leq 17$, and lower $T_{o}, T_{p}, T_{c}, \Delta H_{g e l}$.

\section{ACKNOWLEDGEMENTS}

The authors greatly thank Akita Prefectural University, Japan, Prof. Dr. Yasonori Nakamura for kind assistance on the analysis of chain length of amylopection. This research was sponsored by Research Coordinated Proposal (120609), International Atomic Energy Agency, National Science Foundation of China (30671284), High-Tech 863 Plan, China Ministry of Science and Technology, and Crop Breeding Program, Zhejiang and Yunan Provincial Department of Science and Technology (2007C12007/0406/2006XY12).

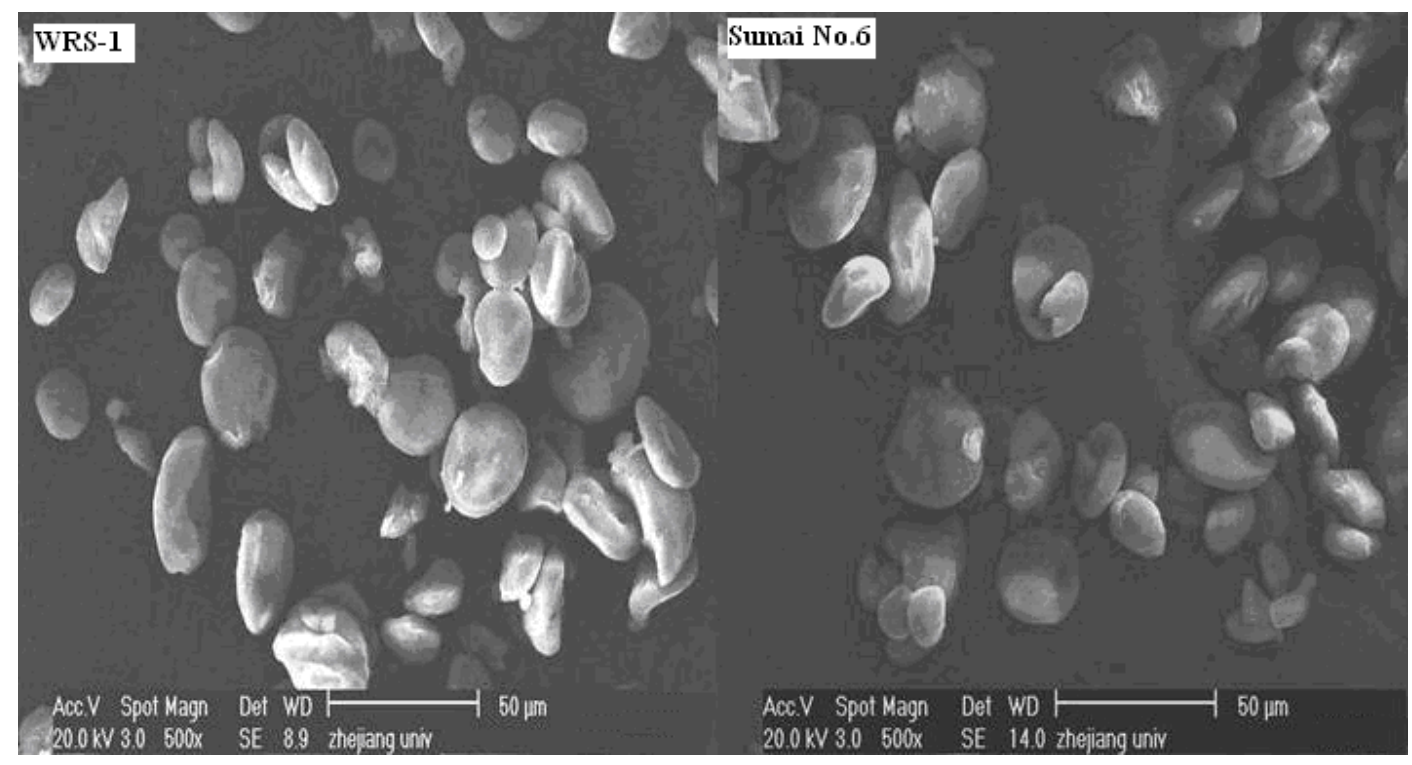

Fig. (3). Scanning electron micrographs (SEM) of starch granules from mutant WRS-1 and wild type 'Sumai No.6' (×500). 

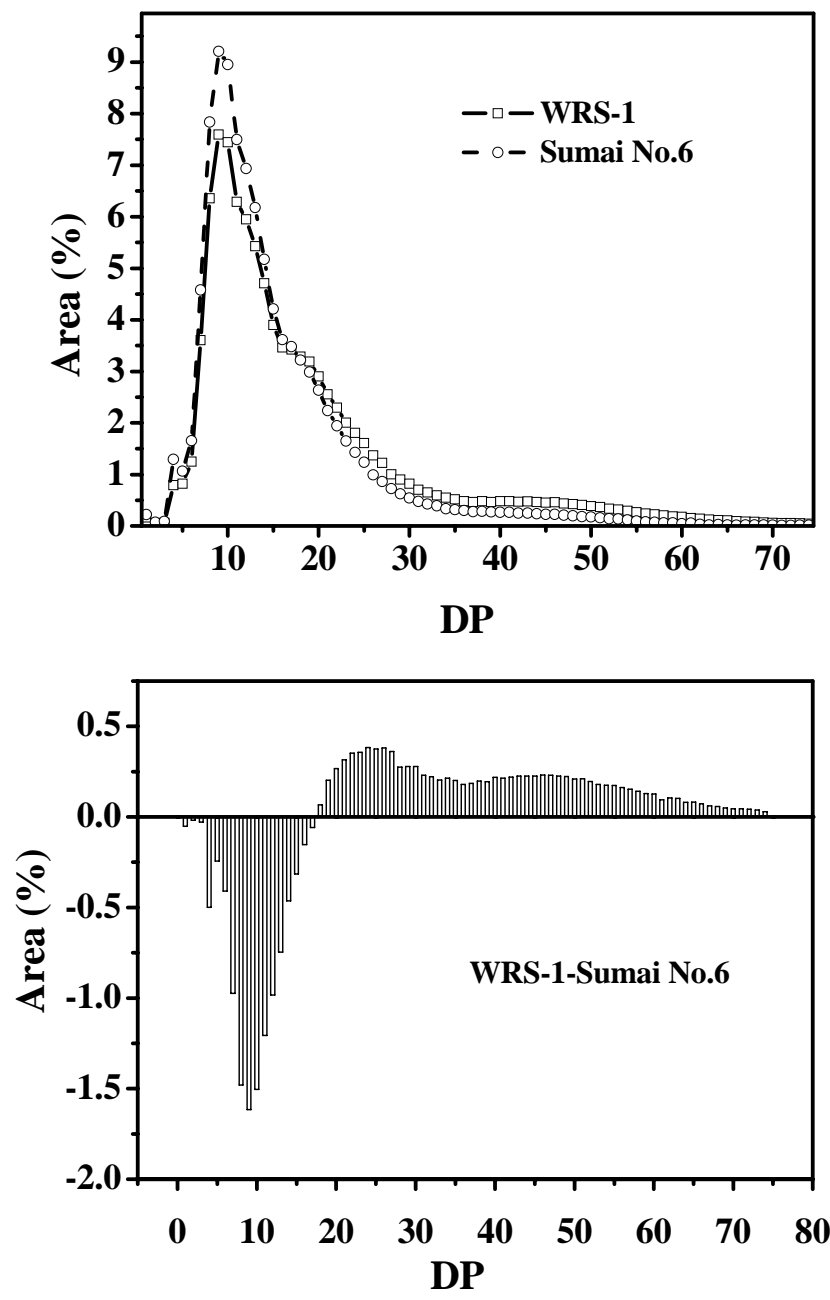

Fig. (4). Chain length of amylopectin in mutant WRS-1 and wild type 'Sumai No.6'.

\section{ABBREVIATIONS}

$\begin{array}{ll}\text { AAC } & =\text { Apparent amylose content } \\ \text { ACR } & =\text { Amylopectin chain ratio } \\ \mathrm{BV} & =\text { Blue value } \\ \mathrm{DSC} & =\text { Differential scanning calorimetry } \\ \mathrm{DP} & =\text { Degree of polymerization } \\ \mathrm{SEM} & =\text { Scanning electron micrographs } \\ T_{c} & =\text { Final temperature } \\ \mathrm{LC} & =\text { Lipid content } \\ T_{o} & =\text { Onset temperature } \\ T_{p} & =\text { Peak temperature } \\ \mathrm{PC} & =\text { Protein content } \\ \mathrm{RS} & =\text { Resistant starch } \\ \Delta H_{g e l} & =\text { The enthalpy of gelatinization } \\ \mathrm{TS} & =\text { Total starch }\end{array}$

[20] Tharanathan M, Tharanathan RN. Resistant starch in wheat-based products: isolation and characterization. J Cereal Sci 2001; 34: 7384.

[21] Regina A, Bird AR, Topping DL, et al. High-amylose wheat generated by RNA interference improves indices of large-bowel health in rats. PNAS 2006; 103: 3546-3551.

[22] Van Der Borght A, Goesaert H, Veraverbeke WS, Delcour JA. Fractionation of wheat and wheat flour into starch and gluten: overview of the main processes and the factors involved. J Cereal Sci 2005; 41: 221.

[23] Hoebler C, Karinthi A, Chiron H, Champ M, Barry JL. Bioavailability of starch in bread rich in amylose: metabolic responses in healthy subjects and starch structure. Eur J Clin Nutr 1999; 53: 360-366.

[24] Muri JG, Yeow EG, Keogh J, et al. Combining wheat bran with resistant starch has more beneficial effects on fecal indexes than does wheat bran alone. Am J Clinl Nutr 2004; 79: 1020-1028.

\section{REFERENCES}

[1] Jobbing S. Improving starch for food and industrial applications. Curr Opin Plant Biol 2004; 7: 210-218.
Anderson JW, Jones AE, Riddell-mason S. Ten different fibers have significantly different effects on serum and liver lipids of cholesterol-fed rats. J Nutr 1994; 124: 78-83.

Behall KM, Scholfield DJ, Hallfrisch J. The effect of particle size of whole-grain flour on plasma glucose, insulin, glucagon and thyroid-stimulating hormone in humans. J Am College Nutr 1999; 18(6): 591-597. 
[27] Jensen MK, Koh-Banerjee P, Franz M, Sampson L, Gronbaek M, Rimm EB. Whole grains, bran, and germ in relation to homocysterine and markers of glycemic control, lipids, and inflammation. Am J Clin Nutr 2006; 83: 275-283.

[28] Brennan CS. Dietary fibre, glycaemic response, and diabetes. Mol Nutr Food Res 2005; 49: 560-570.

[29] Shu XL, Jiao GA, Fitzgerald MA, Yang CZ, Shu QY, Wu DX. Starch structure and digestibility of rice high in resistant starch. Starch/Stärke 2006; 58: 411-417.

[30] Verwimp T, Vandepytte GE, Marrant K. Isolation and characterization of rye starch. J Cereal Sci 2004; 39: 85-90.

[31] Juliano BO, Pascual C. Quality characteristics of milled rice grown in different countries. IRRI Res Paper Ser 1980; 48: 25.

[32] American Association of Cereal Chemists (AACC). 1995. Approved methods the AACC, Ninth Edition, Method 08-10. St. Paul, MN: The Association.

[33] Garcia-Alonso A, Jimenez-Escrig A, Martin-Carron N. Assessment of some parameters involved in the gelatinization and retrogradation of starch. Food Chem 1999; 66: 181-187.

[34] Goñi I, Garcia-Alonso A, Saura-Calixto F. A starch hydrolysis procedure to estimate glycemic index. Nutr Res 1997; 17: 427-437.

[35] Umemoto T, Nakamura Y, Satoh H, Terashima K. Differences in amylopectin structure between two rice varieties in relation to the effects of temperature during grain filling. Starch/Stärke 1999; 51: 58-62.

[36] Nakamura Y, Kubo A, Shimamune T, Matsuda T, Harada K, Satoh $\mathrm{H}$. Correlation between activities of starch debranching enzyme and a-polyglucan structure in endosperm of sugary-1 mutants of rice. Plant J 1997; 12: 143-153.

[37] Englyst KN, Englyst HN, Cumming JH. Rapidly available glucose in foods: an in vitro measurement that reflects the glycemic response. Am J Clin Nutr 1999; 69: 448-454.

[38] Jenkins DJA, Thomas DM, Wolver TMS. Glycemic index of foods: a physiological basis for carbohydrate exchange. Am J Clin Nutr 1981; 34: 362-366.
[39] Gidley ML, Cooke O, Darks AH, Holffmann RA, Rwssel AL, Greenwell P. Molecular order and structure in enzyme resistant retrograded starch. Carbohydr Polym 1995; 28: 23-31.

[40] Rashmi S, Urooj A. Effect of processing on nutritionally important starch fractions in rice varieties. Int J Food Sci Nutr 2003; 54: 2736.

[41] Hu PS, Zhao HJ, Zhang LL, Duan ZY, Wu DX. Starch digestibility and the estimated glycemic score of different types of rice differing in amylose contents. J Cereal Sci 2004; 40: 231-237.

[42] Baum BR, Bailey LG. A survey of endosperm starch granules in the genus Hodeum: a study using image analytic and numerical taxonomic techniques. Can J Bot 1987; 65: 1563-1569.

[43] Peterson DG, Fulcher RG. Variation in Minnesuta HRS wheats: starch granule size distribution. Food Res Int 2001; 34: 357-363.

[44] Singh N, Kaur L, Sandhu KS, Kaur J, Nishiari K. Relationships between physicochemical, morphological, thermal, theological properties of rice starches. Food Hydrocolloids 2006; 20: 532-542.

[45] Shi YC, Seib PA. The structure of four waxy starches related to gelatinization and retrogradation. Carbohydr Res 1992; 227: 131145.

[46] Salomonsson AC, Sundberg B. Amylose content and chain profile of amylopectin from normal, high amylose and waxy barleys. Starch/Starke 1994; 46: 325-328.

[47] Nishi A, Nakamura Y, Tanaka N, Satoh H. Biochemical and genetic analysis of the effects of amylose-extender mutation in rice endosperm. Plant Physiol 2001; 127: 459-472.

[48] Satoh H, Nishi A, Yamashita K, et al. Starch-branching enzyme Ideficient mutation specifically affects the structure and properties of starch in rice endosperm. Plant Physiol 2003; 133: 1111-1121.

[49] Nakamura Y, Sakurai A, Inaba Y, Kimura K, Iwasawa N, Nagamine T. The fine structure of amylopectin in endosperm from Asian cultivated rice can be largely classified into two classes. Starch/Stärke 2002; 54: 117-131. 